\title{
Small cell oesophageal carcinoma: an institutional experience and review of the literature
}

\author{
E Hudson ${ }^{*, 1}$, J Powell', S Mukherjee', TDL Crosby', AE Brewster', TS Maughan', H Bailey' and JF Lester' \\ 'Velindre Hospital, Velindre Road, Whitchurch, Cardiff, CFI4 2TL, UK
}

\begin{abstract}
Primary small cell oesophageal carcinoma (SCOC) is rare, prognosis is poor and there is no established optimum treatment strategy. It shares many clinicopathologic features with small cell carcinoma of the lung; therefore, a similar staging and treatment strategy was adopted. Sixteen cases referred to Velindre hospital between 1998 and 2005 were identified. Patients received platinum-based combination chemotherapy if appropriate. Those with limited disease (LD) received radical radiotherapy (RT) to all sites of disease on completion of chemotherapy. Median survival of all patients was I3.2 months. Median survival of patients with LD was significantly longer than those with extensive disease ( $24.4 \mathrm{vs} 9.1$ months, $P=0.034$ ). This is one of the largest single institution series in the world literature. Combined modality therapy using platinum-based combination chemotherapy and radical RT may allow a nonsurgical approach to management, avoiding the morbidity of oesophagectomy. Prophylactic cranial irradiation is controversial, and should be discussed on an individual basis.
\end{abstract}

British Journal of Cancer (2007) 96, 708-7II. doi:10.1038/sj.bjc.66036II www.bjcancer.com

Published online 13 February 2007

(c) 2007 Cancer Research UK

Keywords: small cell; oesophagus; chemotherapy; radiotherapy

Primary small cell oesophageal carcinoma (SCOC) was first described in 1952 by McKeown (1952), who reported two cases at post mortem examination. It is a rare condition, accounting for between 0.5 and $2.4 \%$ of all primary oesophageal malignancies (Casas et al, 1997). Prognosis is poor and metastases are often present at the time of diagnosis; patients presenting with disease outside the oesophagus have a median survival of only 1 month without treatment (Casas et al, 1997). Owing to its rarity, an optimum treatment strategy has not been established, and various combinations of surgery, radiotherapy (RT), and chemotherapy have been described in the literature.

Small cell lung cancer (SCLC) is a far more common disease, accounting for up to $20 \%$ of all primary lung cancers and it shares many clinicopathologic features with SCOC. There is good evidence that combination chemotherapy significantly increases median survival compared to no systemic therapy or single agent chemotherapy in SCLC (Girling, 1996; Agra et al, 2003). In addition, in SCLC patients with limited disease (LD) and a complete response to chemotherapy, consolidation thoracic irradiation and prophylactic cranial irradiation (PCI) both increase 3-year absolute survival by 5.4\% (Pignon et al, 1992; Auperin et al, 1999). Therefore, a similar staging and treatment strategy for SCOC was adopted. We report our clinical experience using this strategy and review the published literature on SCOC.

*Correspondence: Dr E Hudson;

E-mail: emma.hudson@velindre-tr.wales.nhs.uk

Received 7 November 2006; revised 10 January 2007; accepted 10 January 2007; published online 13 February 2007

\section{MATERIALS AND METHODS}

All cases of SCOC referred to Velindre Cancer Centre, Southeast Wales, between 1998 and 2005, were identified using an electronic database holding information on all treated cancer patients (Information System for Clinical Organisations, ISCO). Data were collected retrospectively from ISCO and by case note review on demographic details, performance status (PS), treatment, and response to treatment. All patients were required to have a histological diagnosis of small cell carcinoma according to WHO criteria (WHO, 1982). Survival was recorded from the date of histological diagnosis. Staging was analogous to that used in SCLC as proposed by the Veterans' Administration Lung Group; LD was defined as a tumour mass contained within the oesophagus or perioesophageal tissues, with or without regional lymph node involvement, such that the disease can be encompassed within a tolerable radiation therapy port, and extensive disease (ED) included all other patients (Zelen, 1973). For the literature review, the electronic databases MEDLINE, EMBASE, and Cancerlit were searched using the key words oesophagus, oesophagus, small cell, neuroendocrine, and gastrointestinal. Hand searching of journals, relevant books, and review articles was also carried out. Survival was calculated using the Kaplan-Meier method.

\section{RESULTS}

Sixteen patients were identified, and their clinical details are summarised in Table 1. The age range of all patients was 48-81 years with a median age of 68.5 years and 12/16 (75\%) patients were female. Histological diagnosis was established by oesophagogastroduodenoscopy and biopsy in all patients. In all cases, pure SCOC was reported with no other histological subtypes identified. In $8 / 16(50 \%)$ patients selected, immunohistochemical staining 
was performed to confirm the diagnosis. Neurone-specific enolase was positive in three patients and CD56 in three patients, supporting the diagnosis of small cell carcinoma. In two patients immunohistochemistry was unhelpful, but a second opinion on the cellular morphology supported the diagnosis of small cell carcinoma. In $8 / 16(50 \%)$ patients the diagnosis was made on the classical histological appearance of small cell carcinoma and immunohistochemistry was not deemed necessary. In total, 13/16 (81\%) patients were staged with a CT scan of the chest and abdomen. Two patients had abdominal ultrasound (Patients 9 and 14) and one patient was deemed too frail for staging investigations (Patient 16). Only one patient (Patient 11) had a bone scan as part of the initial staging investigations. A CT scan of the head was not performed in any patient.

Performance status was recorded in 15/16 (93\%) patients. In total, 10/16 patients had a PS of $0-1,4 / 16$ had a PS of 2 and $1 / 16$ had a PS of 4 . In total, 13/16 patients had disease in the lower-third of the oesophagus and 3/16 had disease in the middlethird. No tumours were identified in the upper-third of the oesophagus.
In total, 6/16 (38\%) patients had LD, and 9/16 (56\%) had ED. Stage was not recorded in $1 / 16(6 \%)$ patient.

Of those with ED, 7/9 (78\%) patients had liver metastases at the time of diagnosis. In total, 6/9 (67\%) patients with ED were given chemotherapy; all received four to six cycles of $\mathrm{PE}$ (carboplatin AUC 5-6 intravenously (i.v.) in combination with oral etoposide 3-weekly). Patients 13 and 15 received palliative RT to the oesophagus following a partial response (PR) to chemotherapy. Three patients (patients 9, 10, and 14) received no chemotherapy because of poor PS, and were managed with best supportive care. Patient 16 (unknown stage) was treated with palliative RT only.

Five of the six patients with LD were given chemotherapy. Patient 3 received six cycles of ICE (carboplatin AUC 6 i.v. ifosfamide $3 \mathrm{gm}^{-2}$ i.v. and oral etoposide 4 -weekly). The other patients received four to six cycles of either PE or CE (cisplatin 60-80 $\mathrm{mgm}^{-2}$ i.v. and oral etoposide 3-weekly). All five patients received $\mathrm{RT}$ to the oesophagus given with curative intent following a PR to chemotherapy. Patients 3 and 4 also received PCI. One patient with LD (Patient 2) was treated at another cancer centre

Table I Clinical and treatment details of the 16 SCC oesophagus patients

\begin{tabular}{|c|c|c|c|c|c|c|c|c|c|c|c|}
\hline Patien & Age & Sex & x PS Stage & e Primary & Site Site of metastases & Chemo (cycles & ) Response & e Oesophageal RT & $\mathbf{P C l}$ & Relapse site & Survival (months) \\
\hline I & 77 & & 0 LD & Lower & & $4 \mathrm{PE}$ & PR & $40 \mathrm{~Gy} / \mathrm{I} 5 \mathrm{~F}$ & & & 104, alive \\
\hline 2 & 71 & M & I LD & Lower & & & & $44 \mathrm{~Gy} / \mathrm{I} 2 \mathrm{~F}$ & & Local, nodal & 19 \\
\hline 3 & 59 & M & 0 LD & Lower & & 6 ICE & PR & $40 \mathrm{~Gy} / \mathrm{I} 5 \mathrm{~F}$ & $30 \mathrm{~Gy} / \mathrm{IOF}$ & & 48, alive \\
\hline 5 & 51 & $\mathrm{~F}$ & 0 LD & Mid & & $4 \mathrm{PE}$ & PR & $45 \mathrm{~Gy} / 25 \mathrm{~F}$ & & Local & 9, alive \\
\hline 6 & 50 & $\mathrm{~F}$ & 0 LD & Mid & & $4 \mathrm{PE}$ & PR & 50 Gy/25F & $30 \mathrm{~Gy} / \mathrm{I} 0 \mathrm{~F}$ & FBone & 14 \\
\hline 7 & 53 & $\mathrm{~F}$ & UKED & Lower & Abdo nodes & $4 \mathrm{PE}$ & PR & $30 \mathrm{~Gy} / \mathrm{IF}$ & & Local & 12 \\
\hline 8 & 67 & $\mathrm{~F}$ & $2 \mathrm{ED}$ & Lower & Liver, spleen & $4 \mathrm{PE}$ & UK & & & UK & 6 \\
\hline 11 & 71 & M & I ED & Lower & Liver & $4 \mathrm{PE}$ & PR & & & PD & 10 \\
\hline 12 & 72 & $\mathrm{~F}$ & I ED & Mid & Liver, lungs, SCF & $6 \mathrm{PE}$ & PR & & & $\mathrm{PD}$ & 30, alive \\
\hline 13 & 71 & $\mathrm{~F}$ & I ED & Lower & Liver & $4 \mathrm{PE}$ & PR & $25 \mathrm{~Gy} / \mathrm{IOF}$ & & Local, liver, brair & $\mathrm{n} 13$ \\
\hline 14 & 65 & $\mathrm{~F}$ & 2 ED & Lower & Liver & & & & & PD & 2 \\
\hline 15 & 58 & M & I ED & Lower & Abdo nodes, pancreas & s 4 PE & PR & 40 Gy/I $5 F$ & & & 7, alive \\
\hline 16 & 81 & $\mathrm{~F}$ & 2 UK & Lower & UK & & & $8 \mathrm{~Gy} / \mathrm{IF}$ & & UK & 7 \\
\hline
\end{tabular}

Abdo = abdominal: $C E=$ cisplatin and etoposide; $D F=$ disease-free; $E D=$ extensive disease; $F=$ female; $I C E=$ ifosphamide, cisplatin and etoposide; $L D=$ limited disease: $\mathrm{M}=$ male; $\mathrm{PE}=$ carboplatin and etoposide; $\mathrm{PCl}=$ prophylactic cranial irradiation; $\mathrm{PS}=$ performance status; $\mathrm{PR}=$ partial response; $\mathrm{RT}=$ radiotherapy; $\mathrm{SCF}=$ supraclavicular fossa; UK, unknown

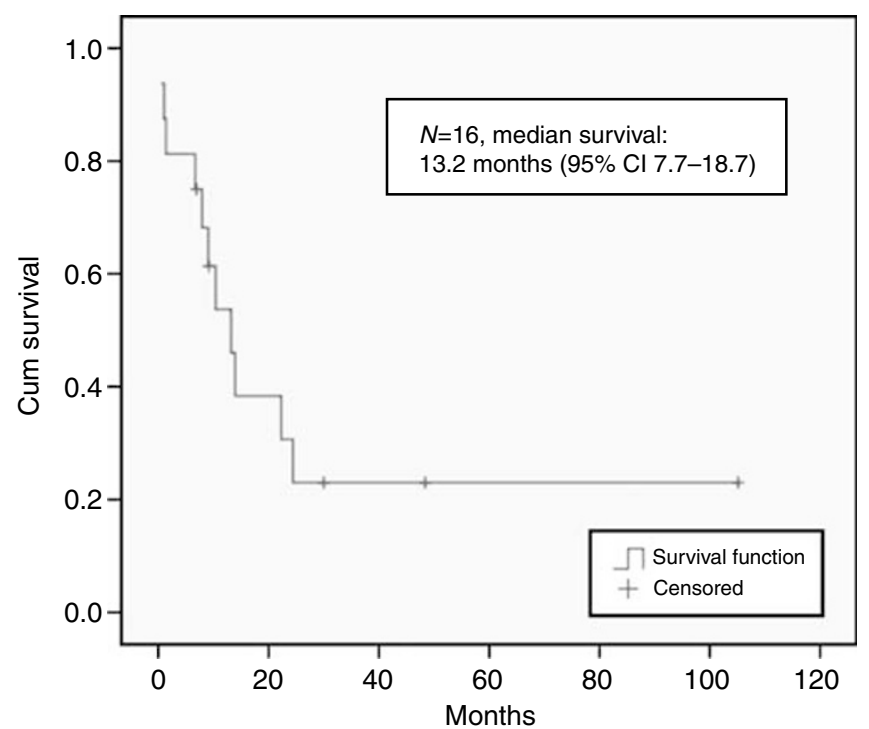

Figure I Overall survival of all patients with SCC oesophagus.

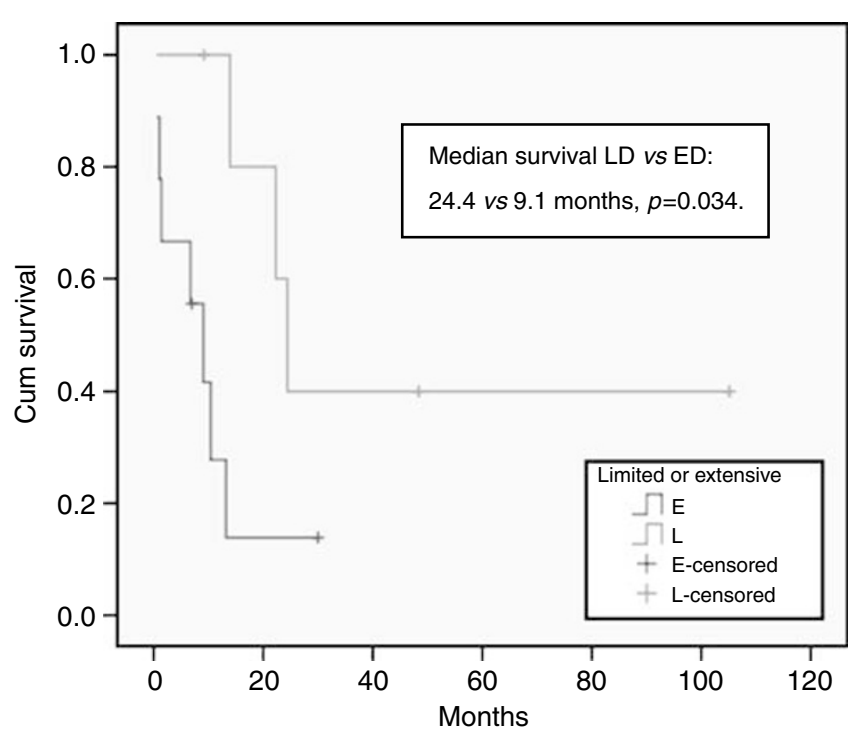

Figure 2 Overall survival of patients with limited vs ED. 
with radical RT alone. His subsequent treatment was carried out at Velindre hospital.

Radiotherapy to the oesophagus was given 3-4 weeks after the last cycle of chemotherapy. The dose given was $30-50 \mathrm{~Gy}$ in $12-25$ fractions over 2-5 weeks using megavoltage photons. Treatment was $2 \mathrm{D}$ or $3 \mathrm{D}$-planned to cover all areas of disease including any involved lymph nodes. When used, PCI was given concurrently with RT to the oesophagus. The median survival of all 16 patients was 13.2 months (95\% CI 7.7-18.7), and is shown in Figure 1.

To date, 7/9 (78\%) patients with ED have died. Patients 12 and 15 are alive 30 and 7 months after diagnosis, respectively. The median survival of all patients with ED is 9.1 months (95\%CI $3.3-14.8)$.

Of the six patients with LD, patients 1 and 3 are alive with no evidence of recurrent disease, 104 and 48 months after diagnosis respectively. Patient 5 is alive 9 months after diagnosis but has relapsed locally. Patient 2 relapsed locally and died 19 months after diagnosis. Patient 4 developed malignant ascites and patient 6 bone metastases, dying 24 and 14 months after diagnosis, respectively. The median survival of all patients with LD was 24.4 months (95\% CI 19.9-28.9), which was significantly longer than those with $\mathrm{ED}(P=0.034$; Figure 2$)$.

\section{DISCUSSION}

Primary SCOC is a relatively rare condition, and we have reported one of the largest single-institution series in world literature. The largest retrospective analysis has been carried out by Casas et al (1997), who analysed data on 199 evaluable patients found in the literature. They reported a male / female ratio of $1.57: 1$, with $95 \%$ of tumours situated in the mid- and lower oesophagus. One-third of cases were mixed tumours with squamous differentiation also identified in addition to small sell carcinoma. Our series has a male / female ratio of $1: 4$, which is at variance with all other published literature on SCOC. The relatively small sample size may in part explain the difference, but a recent increase in the proportion of female smokers may also play a role. We identified no tumours in the upper-third of the oesophagus, concurring with Casas et al, (1997). All tumours were pure small cell carcinoma with no mixed tumours reported. However, none of our patients had surgery, and the absence of other histological subtypes may simply reflect the small size of the tissue samples examined at the time of diagnosis. More than half of patients in our series had metastatic disease at diagnosis, as in most other published series (Casas et al, 1997). This is similar to SCLC, indicating SCOC is an aggressive, systemic disease. The rarity of SCOC and absence of randomised trials means the optimum treatment strategy remains unclear.

For the treatment of LD with curative intent, RT alone has been used; however, results generally have been disappointing and longterm survivors are only rarely reported (Doherty et al, 1984; Huncharek et al, 1995; Medgysey et al, 2000). The only patient in our series treated with radical RT alone died 19 months after diagnosis.

There are few reports of surgery being used as the sole treatment modality and, as with RT, most institutional series report a poor outcome with surgery alone. Hosokawa et al (2005) reported on five LD patients treated with radical oesophagectomy alone, and only one patient survived more than 24 months. Craig et al (1995) reported on five patients treated with surgery alone, and only one survived more than 12 months. Law et al (1994) treated three patients with radical oesophagectomy with a median survival of 11.6 months.

The role of chemotherapy in SCLC is well established (Agra et al, 2005; Girling, 1996). Evidence suggests that extrapulmonary small cell carcinoma is also a chemosensitive disease (Lester et al, 2006; Levenson et al, 1981).There is a general consensus in the recent literature that systemic chemotherapy should also be used in the treatment of SCOC. Casas et al (1997) reported a median survival of 20 months in those patients receiving systemic chemotherapy compared to only 5 months in those having local treatment only. Performance status was poorly reported in the series included in the Casas review; good PS is a better prognostic factor in SCLC (Bremnes et al, 2003), and it is reasonable to assume it is so in SCC. Poor PS patients tend not be given chemotherapy, and the longer survival in the chemotherapy group may therefore be owing in part to the better PS of these patients. As a result of relatively poor outcomes using local treatment only and the apparent chemosensitivity of SCOC, combined modality treatment strategies were developed. The MD Anderson Cancer Center reported on four LD patients treated with chemotherapy followed by RT and/or oesophagectomy. One patient remains alive and disease-free, 57 months after diagnosis (Medgysey et al, 2000). Craig et al (1995) reported a patient surviving 96 months after oesophagectomy and adjuvant chemotherapy. In our series, of the six patients with LD, two are alive with no evidence of recurrent disease 47 and 79 months after diagnosis, respectively. Both received chemotherapy followed by RT to all sites of disease.

Patients with LD were offered PCI at the discretion of the treating oncologist. PCI in SCLC patients with LD has been shown to decrease the incidence of brain metastases from 59 to $33 \%$, and increase 3 -year absolute survival by $5.4 \%$. The incidence of brain metastases in SCOC is not known, and to our knowledge, no study has been reported on the use of PCI in SCOC. To date, none of the patients with LD has relapsed in the brain and only two patients had PCI.

\section{CONCLUSION}

Caution should be applied in basing treatment strategies on retrospective data, as poor record keeping and bias may influence results. However, for localised disease it does seem that combined modality therapy using platinum-based combination chemotherapy and RT to the oesophagus may provide effective local control and avoid the morbidity of extensive surgery. Oesophagectomy or RT alone are probably inadequate, and if used, should be combined with adjuvant or neoadjuvant platinum-based chemotherapy. The role of PCI is controversial, and should be discussed with patients on an individual basis. For those patients presenting with metastases, palliative chemotherapy may prolong survival, and RT can be used for local control in selected good PS patients.

\section{REFERENCES}

Agra Y, Pelayo M, Sacristan M, Sacristan A, Serra C, Bonfill X (2003) Chemotherapy versus best supportive care for extensive small cell lung cancer. Cochrane Database of Systematic Reviews 4: CD001990

Auperin A, Arriagada R, Pignon JP, Le Pechoux C, Gregor A, Stephens RJ, Kristjansen PE, Johnson BE, Ueoka H, Wagner H, Aisner J (1999)

Prophylactic cranial irradiation for patients with small-cell lung cancer in complete remission. $N$ Engl J Med 341: 476-484

Bremnes RM, Sundstrom S, Aasebo U, Kaasa S, Hatlevoll R, Aamdal S (2003) Norwegian lung cancer study group the value of prognostic factors in small cell lung cancer: results from a randomised multicenter study with minimum 5 year follow-up. Lung Cancer 39: 303-313 
Casas F, Ferrer F, Farrus B, Casals J, Biete A (1997) Primary small cell carcinoma of the esophagus: a review of the literature with emphasis on therapy and prognosis. Cancer 80: $1366-1372$

Craig SR, Carey FA, Walker WS, Cameron EW (1995) Primary small-cell cancer of the esophagus. J Thorac Cardiovasc Surg 109: 284-288

Doherty MA, McIntyre M, Arnott SJ (1984) Oat cell carcinoma of esophagus: a report of six British patients with a review of the literature. Int J Radiat Oncol Biol Phys 10: $147-152$

Girling DJ (1996) Comparison of oral etoposide and standard intravenous multidrug chemotherapy for small-cell lung cancer: a stopped multicentre randomised trial. Lancet 348: 563-566

Hosokawa A, Shimada Y, Matsumura Y, Yamada Y, Muro K, Hamaguchi T, Igaki H, Tachimori Y, Kato H, Shirao K (2005) Small cell carcinoma of the esophagus analysis of 14 cases and literature review. Hepatogastroenterology 52: $1738-1741$

Huncharek M, Muscat J (1995) Small cell carcinoma of the esophagus. The Massachusetts General Hospital experience, 1978 to 1993. Chest 107: $179-181$

Law SY, Fok M, Lam KY, Loke SL, Ma LT, Wong J (1994) Small cell carcinoma of the esophagus. Cancer 73: 2894-2899
Lester JF, Hudson E, Barber JB (2006) Bladder preservation in small cell carcinoma of the urinary bladder: an institutional experience and review of the literature. Clin Oncol 18: 608-611

Levenson Jr RM, Ihde DC, Matthews MJ, Cohen MH, Gazdar AF, Bunn Jr PA, Minna JD (1981) Small cell carcinoma presenting as an extrapulmonary neoplasm: sites of origin and response to chemotherapy. J Natl Cancer Inst 67: 607-612

Mckeown F (1952) Oat cell carcinoma of the oesophagus. J Pathol Bacteriol 64: $889-891$

Medgysey CD, Wolff RA, Putnam Jr JB, Ajani JA (2000) Small cell carcinoma of the esophagus: the University of Texas M. D. Anderson cancer center experience and literature review. Cancer 88: 262-267

Pignon JP, Arriagada R, Ihde DC, Johnson DH, Perry MC, Souhami RL, Brodin O, Joss RA, Kies MS, Lebeau B (1992) A meta-analysis of thoracic radiotherapy for small-cell lung cancer. $N$ Engl J Med 327: $1618-1624$

The World Health Organisation. Histological typing of lung tumours. second edition (1982) Am J Clin Pathol 77: 123-136

Zelen M (1973) Keynote address on biostatistics and data retrieval, part 3 Cancer Chemother Rep 4: 31-42 